\title{
Assessment of Alienation among the Madrasa Students
}

$$
\text { of Kashmir Valley }
$$

\author{
Mohammad Ashraf Malik ${ }^{1}$
}

\section{ABSTRACT:}

Background: In the Muslim world Madrasa is the main source of education. Throughout the world Madrasas are imparting education to Muslim students. Due to lack of modern education and Urdu medium system in the Madrasa, the students enrolled in these Madrasa could not compete with the other students. So, they face lot of problems in making their psychological and social adjustment. They get alienated from themselves and their society because their degree's are not recognized anywhere. This creates lot of difficulties in getting jobs.

Objective: The main objective of paper is to assess the level of alienation among male and female madrasa students.

Method: The present study was conducted on the sample of 120 male and female Madrasa students. The data was collected from the Kashmir (India). For the purpose of data collection from different Madrasa students, alienation scale developed by Kureshi and Dutt (1979) was administered on subjects. The subjects were randomly selected. For the result purposes Mean, S.D. and $\mathrm{t}$-test were calculated.

Results: The results showed that both male and female madrasa students are experience the level of alienation. However, on the basis of mean score male students shows high mean score $(\mathrm{M}=48.98)$ as compared to female students $(\mathrm{M}=44.98)$. While as no siginificant difference were found in their alienation scores.

Conclusion: Alienation was found to be common in madrasa students especially in male as compared to female students. There is need of further research in this area. So that this problem could be highlighted and addressed in order to prepare and to generate the coping ability among them.

Keywords: Alienation, Madrasa, Students, Education, Kashmir

\section{INTRODUCTION:}

Alienation is the lack of association feeling, feeling of separation from family, friends and friends (Bronfenbrenner, 1986). The term alienation is derived from the word alien means 'foreign' or estranged.

\footnotetext{
${ }^{1}$ Research scholar, Department of Psychology, AMU, Aligarh (India)
}

(C) 2015 I M Malik; licensee IJIP. This is an Open Access Research distributed under the terms of the Creative Commons Attribution License (http://creativecommons.org/licenses/by/2.0), which permits unrestricted use, distribution, and reproduction in any Medium, provided the original work is properly cited. 
In other words alienation can be describes the condition of the subject who no longer recognizes himself or rather can only recognize himself by others. If this is the mean that is chosen, the man who alienated would in some sense be foreign or separated from himself. He is stranger in his own society, one who does not belong to anywhere or anybody. The concept of alienation originated from Hegel who denotes the distance between mind and reality, and denotes states causing self-alienation, loss of self-identity, and feeling of depersonalization, cause of which may be traced back to some environmental pressures.The characteristics of alienated individual include a tendency in his own fanciful world, resenting and rejecting the norms and traditions of society. Thus he may give way to his uncontrolled desires thereby distracting the harmonious relationship between himself and society. This way he becomes estranged from the outside world.

Alienation has been found to be related with loss of self, anxiety state, depersonalization, restlessness apathy, social disorganization, loneliness, atomization, powerlessness, meaningfulness, isolation, pessimism, and the loss of belief or value (Josephson, 1962).

Alienation may be viewed as a result of pervasive social forces beyond schools, such as specialization, mobility, bureaucratization, capitalism, or other features of the modern world that fragment human experience (Davison, Aviles, Guerrero, Howarth, \& Thomas,1999). Alienation is term used to describe students estrangement in the learning process (Brown, Higgins, \&Paulsen,2003). Social estrangement is the result of a student's inability or unwillingness to integrate into school's social existing network (Brown et.al. 2003). A student who feels estranged typically doesn't accept the goals and values of a school and tends to reject school and all that it stands for (Rafalides \& Hoy, 1971).

According to the Brown et. al (2003) "when students believe that, they can personally do influence their future in school, they disengage from process". These students learn that their complaint and concerns go unheard and eventually rebellious behavior such as skipping class, not doing or turning in homework, and thwarting school norms and rules replace efforts to learn (Mau,1992).

\section{OBJECTIVES}

1. To study the level alienation among male and female madras students.

2. To examine the significant difference between the male and female madrasa students of in their level of alienation. 


\section{HYPOTHESES}

1. There is no significant difference between the real mean and the assumed among male and female madras students in their level of alienation.

2. There is no significant difference between the male and female students of madrasa in their level of alienation.

\section{METHODOLOGY}

\section{Sample}

The present study was conducted on the sample of 120 madrasa students both male and female. The subjects were randomly selected. Out of the total sample 60 were male and 60 were females.

\section{Tool used}

In the present study for the measurement of alienation among Madrassas students, Kureshi \& Dutt (1979) alienation scale was used to collected data from the subjects. The scale consists of 21 items and each item is followed by four alternative options that ranges from 'always' to 'never' representing the five factors despair, disillusionment, unstructured universe, psychological vacuum and narcissism. Out of these 21 items, the item no's. 3,12,18,21 are negative items. The scoring for the all other items except form the negative ones is 4,3,2,1. While as negative items are scored as, 1,2,3,4. The cut of score for detecting individual sense of alienation is 42 or above. The reliability of the scale calculated through Cronbach's Alpha was found .76 .

\section{Procedure}

First of all, the investigator met the participants personally and explained them the purpose of the present study. Then after, the investigator established rapport with the participants and requested them to participate voluntarily and cooperate in the data collection process and assured them that their responses would be kept confidential and utilized for the research purposes only. The participants were asked to read the instructions carefully given on the top of each scale. They were also requested to answer all the statements given in the scales sincerely. After receiving their consent, alienation scale, along with personal data sheet were administered to madrasa students.

\section{Data analysis}

For the result purpose, the data was analyzed by using statistical package for social science (SPSS) version 16.0 according to the research questions. Mean and S.D and t-test were applied to know difference in the level of alienation among male and female madrasa students. 


\section{RESULTS}

To know the level of alienation among male and female madrasa students the inferential statistics Mean, S.D., and t-test for one-sample were applied. The results are givenas below:

Hypothesis: 1. There is no significant difference between the real mean and the assumed mean among male and female madrasas students in their level of alienation.

Table No -1. Result of t-test for one sample

\begin{tabular}{|l|l|l|l|l|l|l|l|}
\hline Groups & N & $\begin{array}{l}\text { Real } \\
\text { Mean }\end{array}$ & Test Value & S.D. & Df & T & Level of Sig. \\
\hline Male & 60 & 48.38 & 50 & 9.033 & 59 & 1.38 & Sig. at .01 \\
\hline Female & 60 & 44.98 & 50 & 8.621 & 59 & 4.50 & Sig. at .05 \\
\hline
\end{tabular}

Result given in table-1, shows that the level of alienation among male and female Madrasa students. In male students real mean is (48.38) which is lower than the assumed mean (i.e., 50) but the $\mathrm{t}$-value $(\mathrm{t}=1.38)$ is significant at 0.01 level. Similarly the real mean among female is (44.98)is also lower than the assumed mean (i.e., 50) while as $t$-value $(t=4.50)$ is significant at 0.05 level. This confirms the rejection of null hypothesis, There is no significant difference between the real mean and the assumed mean among male and female madrasa students in their level of alienation.

Hypothesis:2, There is no significant difference between male and female madras students of in their level of alienation.

Table-2.Comparison between male and female madrasa Students in their level of alienation

\begin{tabular}{|l|l|l|l|l|l|l|}
\hline Groups & $\mathbf{N}$ & Mean & S.D. & SE..D & T & Level of sig. \\
\hline MALE & 60 & 48.98 & 9.033 & 1.612 & .037 & In Sig. \\
\cline { 1 - 4 } & 60 & 44.98 & 8.621 & 1.612 & & \\
\hline \multicolumn{7}{|l|}{} \\
\hline
\end{tabular}

The table-2, depicts that the difference between the mean score of male and female students of madrasa in their level of alienation is (48.98) and (44.98) respectively .The standard deviation of both the groups are (9.033) and (8.621). The $\mathrm{t}$-value $(\mathrm{t}=.037)$ is not significant because it fails to reach the significance level criterion. This indicates that both the groups did not differsignificantly in their alienation score. Hence both male and female students are experiencing equal amount of alienation. 


\section{DISCUSSION}

The present investigation was aimed to measure the level of alienation among male and female madrasa students of Kashmir. As noticed in results both male and female students are experiencing the feeling of alienation but on the basis of mean score differences in alienation, male students is slightly higher than the female students which means that male students are more prone to the alienation as compared to females madrasa students and in addition to this significant differences between real mean and assumed mean were found in their alienation scores. ThusH1 is rejected. Further, when the both of the groups were compared, it has been observed that no significance differencewere found in their alienation scores. Hence $\mathrm{H} 2$ was accepted.

The whole result suggested that both males as well as female madrasa students are equally experiencing the alienation. There may be several reasons for this like lack of of reorganization and modern education which keeps them at bay when they are comparing themselves with other students. The other issues are lack of skilled teachers, libraries, modern curriculum and books are also vibrant causes for alienation among them. Usually they are abided with the Islamic education while as least focus is given towards other modern subjects like science, mathematics, English etc. which is the need of hour. Similarly the conservative thinking and negative parental attitudes towards girl education especially regarding modern education are also an important factor.

\section{CLINICAL IMPLICATION}

- The main aim of this study was to measure level of alienation among madrasa students. Alienation is believed to be common variable found among students.

- Alienation is said to be root cause of health problems like depression, stress, anxiety, etc. among students, in this regard psychologist can play important role in generating ability a coping skill among them.

- Madrasa students loss their identity because their degrees are least recognized, so they could not compete with the other modern school students and that make feel them down and they lost their self confidence. In this regard a proper psycho social intervention could help them to restore their self confidence and belief.

\section{LIMITATIONS}

- In the present study on gender was taken into consideration while as other demographical variables like age, residential status, socio-economic status etc. was not included into the study.

- The Study was conducted on the 120 madrasa students. 


\section{REFERENCES}

Bronfenbrenner, U.(1986).Alienation and four world of childhood. Phi Delta Kappan,67,430436

Brown, M.R., Higgins, K., Paulsen, K.(2003). adolescent alienation: What is it and what can educators do about it? Mid-Western Educational Researcher,8(2),23-29

Davison-Aviles, R. M.,Guerrero, M.P.,Howarth,H.B.,\& Thomas,G.(1999). Perception of Chicano/Latino students who have dropped out of school. Journal of Counselling \&Development,77(4),465-467

Josephson ,J.(1962).Man alone; Alienation in modern society.New York: Dell.

Mau,R.Y.(1992). The validity and devolution of a concept: Student alienation. adolescence,27,721-741.

Rafalides,M.\&Hoy,W.(1971). Student sense of alienation and pupil controle orientation of high schools, The High School Journal,55,101-111

Upadhyay.R. (2003)Madrasa Education In India- Is It To Sustain Medieval Attitude Among Muslims? Paper no.730. 